\title{
Potencial Competitivo de Cultivares de Soja em Relação Às Plantas Daninhas ${ }^{1}$
}

\author{
Competitive Potential of Soybean Cultivars Against Weeds
}

\author{
PIRES, F.R. ${ }^{2}$, MENEZES, C.C.E. ${ }^{3}$, PROCÓPIO, S.O. ${ }^{2}$, BARROSO, A.L.L. ${ }^{2}$, MENEZES, J.F.S. ${ }^{2}$, \\ LEONARDO L.M. ${ }^{4}$, SOUSA, J.P.G. ${ }^{4}$, VIEIRA, A.B. ${ }^{4}$ e ZANATTA, J.F. ${ }^{5}$
}

\begin{abstract}
RESUMO - A utilização de métodos culturais no manejo de plantas daninhas é sempre importante dentro de sistemas agrícolas conservacionistas e que visam uma menor quantidade de herbicidas no ambiente. A escolha de cultivares mais competitivos com as espécies infestantes é mais uma ferramenta dentro do manejo integrado de plantas daninhas em lavouras de soja, bem como em outras culturas. Com o objetivo de avaliar o potencial competitivo de cultivares de soja difundidos no sudoeste de Goiás, em relação às plantas daninhas, visando recomendá-los para cultivo em áreas com histórico de alta densidade de espécies infestantes, foram conduzidos dois experimentos a campo em Rio Verde, GO, sendo avaliados quatro cultivares de soja de ciclo precoce no experimento 1: Monsoy 6101, Monsoy 8001, Emgopa 316 e Coodetec 204; e quatro de ciclo médio no experimento 2: Conquista, Codetec 211, Emgopa 315 e Vencedora. Também foram avaliados dois tipos de manejo de plantas daninhas: área capinada manualmente (sem plantas daninhas) e área não-capinada (com infestação de plantas daninhas). Aos 16, 25 e 46 dias após a semeadura (DAS), avaliaramse a altura média e a biomassa seca de plantas; aos 63 DAS, a porcentagem de cobertura do solo pelos cultivares de soja; e, ao final do ciclo, o rendimento de grãos. Todos os cultivares de soja, de ciclo precoce ou médio, exibiram queda no rendimento de grãos com o não-controle das plantas daninhas. Emgopa 316 e Coodetec 204 mostraram ser mais competitivos, entre os de ciclo precoce, no controle de plantas daninhas. O mesmo aconteceu com o cultivar Emgopa 315, entre os de ciclo médio. Estes últimos são os mais indicados para serem cultivados em áreas com maior incidência de plantas daninhas.
\end{abstract}

Palavras-chave: Glycine max, plantas daninhas, competição.

\begin{abstract}
The use of cultural methods in conservationist agricultural system is important for weed management, since it decreases the amount of the chemical products applied. The use of more competitive cultivars seems to be one of the most important weed management methods, which valid for soybean as well as other crops. Two field experiments were carried out to evaluate the competitive potential of soybean varieties, among those officially recommended for southwestern Goiás, against weeds in Rio Verde,GO aiming to propose the cultivation of better-quality varieties in areas with high weed pressure. Four short-season soybean varieties were evaluated in experiment 1: (Monsoy 6101, Monsoy 8001, Emgopa 316 and Coodetec 204) and four medium-season soybean varieties in experiment 2 (Conquista, Coodetec 211, Emgopa 315 and Vencedora). All the cultivars were evaluated under both weed management systems, i.e., manual weed control (absence of weeds) and no weed control (presence of weeds). At the $16^{\text {th }}, 25^{\text {th }}$ and $46^{\text {th }}$ days after sowing (DAS), both plant height and plant dry matter were evaluated; at the $63^{\text {rd }} D A S$, the percentage of soil covered by the soybean cultivars was evaluated and at the end of the plant season, yield was evaluated. All the cultivars displayed yield reduction in the system with no weed control. However, Emgopa 316 and Coodetec 204 were found to be the most competitive among the short-season cultivars. Among the mediumseason cultivars, Emgopa 315 showed the same tendency. Therefore, these two varieties are the most recommended to be cultivated in areas with high weed pressure.
\end{abstract}

Key words: Glycine max, weeds, competition.

Recebido para publicação em 17/3/2005 e na forma revisada em 25/11/2005.

Professor da Faculdade de Agronomia da Universidade de Rio Verde - FESURV, Caixa Postal 104, 75901-970 Rio Verde-GO, <frpires@fesurv.br>. ${ }^{3}$ Agrônomo da COMIGO, Rio Verde-GO. ${ }^{4}$ Acadêmico de Agronomia - FESURV. ${ }^{5}$ Mestrando em Fitossanidade pela Universidade Federal de Pelotas - UFPel. 


\section{INTRODUÇÃO}

Decisões de controle de plantas daninhas em lavouras de soja com base nas espécies e intensidades presentes, bem como nas reduções que causam nos rendimentos da cultura, são necessárias dentro das perspectivas de uma agricultura eficiente e atual. As perdas no rendimento das culturas causadas pela interferência das plantas daninhas são variáveis com as condições de manejo da lavoura. Dentro desse panorama, deve-se considerar que a utilização de herbicidas pode representar em torno de $30 \%$ do custo total de produção (Silva et al., 2000).

A utilização de métodos culturais no manejo de plantas daninhas é sempre importante dentro de sistemas agrícolas conservacionistas e que visam uma menor quantidade de herbicidas no ambiente. Blackshaw et al. (2000) destacam também a importância do emprego desses métodos em situações em que o controle químico para determinada espécie seja limitado pela indisponibilidade de herbicidas seletivos. Nesse contexto, o manejo integrado de plantas daninhas (MIPD) é preconizado, devendo ser utilizado um conjunto de práticas de controle. A crescente utilização do sistema de semeadura direta resulta na indisponibilidade de uso de métodos mecânicos de manejo de plantas daninhas e, dependendo da eficiência na adoção do sistema, pode ocasionar maior dificuldade de controle dessas plantas, com conseqüente incremento da necessidade de uso de herbicidas em algumas culturas (Johnson et al., 1989). Todavia, os métodos culturais podem ser adotados em qualquer sistema de cultivo.

A utilização em conjunto de diversas práticas no controle de plantas daninhas permite uma complementação entre elas e resulta no aumento da eficiência de controle (Merotto Jr. et al., 2001). Segundo Cox et al. (1999), a racionalização do uso do ambiente, em algumas regiões, tem sido alcançada por meio do estabelecimento de metas progressivas de menor impacto ao meio, em que os fundamentos do MIPD são usados como estratégias para o controle de plantas daninhas.

A primeira prática importante a considerar na adoção do manejo cultural de plantas daninhas é a escolha de cultivares que apresentem elevada habilidade competitiva com as espécies infestantes. A velocidade de crescimento inicial está diretamente ligada, entre outros fatores, ao aproveitamento da radiação solar no início do ciclo das plantas cultivadas (Almeida et al., 1998). Além disso, o rápido crescimento das raízes permanentes maximiza o aproveitamento de água e de nutrientes pela cultura (Seibert \& Pearce, 1993).

Resultados na redução do espaçamento entre as linhas da soja demonstraram que esta técnica pode melhorar o controle de plantas daninhas e o rendimento dessa cultura (Johnson et al., 1997). Em estudo conduzido por Puricelli et al. (2003), a produção de biomassa das plantas de soja aos 40 dias após a semeadura foi maior em espaçamentos estreitos do que em espaçamentos largos, mostrando maior habilidade competitiva da soja com a planta daninha Anoda cristata em espaçamentos reduzidos.

O sucesso da competição da soja com as plantas daninhas tem sido atribuído às características do crescimento dos cultivares, dentre as quais podem ser citadas a velocidade de emergência, a altura de plantas, o acúmulo de biomassa, a arquitetura do dossel (Shaw et al., 1997) e o arranjo espacial da cultura, pois a luz é um dos recursos pelo qual as plantas daninhas competem com as culturas. Características críticas de competição por luz incluem taxa de crescimento e altura das plantas (Lindquist et al., 1998). Tollenaar et al. (1994) relatam que o aumento na interceptação da luz pela cultura da soja foi devido ao aumento de densidade de plantas de soja e à redução no espaçamento entre as linhas da cultura.

O objetivo deste trabalho foi avaliar o potencial competitivo de cultivares de soja, amplamente empregados no sudoeste de Goiás, no controle de plantas daninhas, a fim de selecionar os mais promissores, visando o seu direcionamento para cultivo em áreas com histórico de alta densidade de plantas daninhas.

\section{MATERIAL E MÉTODOS}

Foram conduzidos dois experimentos a campo, localizado no Centro Tecnológico (CTC) 
da Cooperativa Mista dos Produtores Rurais do Sudoeste Goiano (COMIGO), em Rio Verde-GO. No primeiro experimento (experimento 1) utilizaram-se cultivares de soja de ciclo precoce e, no segundo (experimento 2), cultivares de soja de ciclo médio. Os dois experimentos foram conduzidos simultaneamente, no período de novembro de 2003 a março de 2004 . O solo das áreas experimentais é classificado como Latossolo Vermelho-Amarelo.

Os tratamentos foram dispostos no delineamento experimental de blocos casualizados com parcelas subdivididas, com quatro repetições. O fator principal foi formado por quatro cultivares de soja, sendo, para o experimento 1, Monsoy 6101, Monsoy 8001, Emgopa 316 e Coodetec 204 (ciclo precoce); e para o experimento 2, Conquista, Codetec 211, Emgopa 315 e Vencedora (ciclo médio). O fator da subparcela consistiu de dois tipos de manejo de plantas daninhas: área capinada manualmente (sem infestação de plantas daninhas por todo o ciclo dos cultivares) e área não-capinada (com infestação de plantas daninhas por todo o ciclo dos cultivares). As capinas foram realizadas a cada 15 dias, até o completo fechamento da soja.

Um dia antes da implantação do experimento, a área foi dessecada quimicamente, utilizando-se o herbicida glyphosate na dose de $1.152 \mathrm{~g} \mathrm{ha}^{-1}$.

Antes da semeadura, foram realizados testes de germinação nas sementes de todos os cultivares avaliados, sendo verificado que todos apresentavam valores superiores a $92 \%$. Também, antes da semeadura, as sementes foram tratadas com fungicida carbendazim + tiram (30 g + 70 g i.a. $100 \mathrm{~kg}^{-1}$ de sementes) e inoculante líquido, cujas estirpes utilizadas foram SEMIA 5079 e 5080, ambas pertencentes à espécie Bradyrhizobium japonicum $(150 \mathrm{~mL}$ $50 \mathrm{~kg}^{-1}$ de sementes, correspondendo a uma concentração de $2,0 \times 10^{9}$ células de rizóbio por $\mathrm{mL}$ ).

Foi adotado o sistema de semeadura direta na área experimental. O espaçamento utilizado nos dois experimentos foi de $0,50 \mathrm{~m}$. A semeadura foi feita no dia 11 de novembro de 2003, mecanicamente, sendo a semeadora regulada para liberar 24 sementes $\mathrm{m}^{-1}$ no experimento 1 e 18 sementes $\mathrm{m}^{-1}$ no experimento
2. A adubação de semeadura foi realizada de acordo com análise de solo e com as necessidades da cultura da soja, sendo de $350 \mathrm{~kg} \mathrm{ha}^{-1}$ da fórmula NPK (2-20-18). As dimensões das subparcelas foram de $2 \times 3 \mathrm{~m}$, utilizando-se uma área útil de $1,5 \times 2 \mathrm{~m}$ (comprimento $\mathrm{x}$ largura).

Aos 35 dias após a semeadura foi feito um levantamento nas parcelas não-capinadas, nas quais as plantas daninhas presentes foram erva-de-santa-luzia (Chamaesyce hirta) (25 plantas $\mathrm{m}^{-2}$ ), mentinha (Leucas martinicensis) (20 plantas $\mathrm{m}^{-2}$ ), timbete (Cenchrus echinatus) (11 plantas $\mathrm{m}^{-2}$ ), trapoeraba (Commelina benghalensis) ( 8 plantas $\left.\mathrm{m}^{-2}\right)$ e joá-de-capote (Nicandra physaloides) (4 plantas $\mathrm{m}^{-2}$ ).

Durante a condução dos experimentos foram realizadas as seguintes avaliações, na área útil de cada subparcela: altura média de plantas aos 16, 25 e 46 dias após a semeadura (DAS), adotando-se como base para medição o meristema apical de cinco plantas em cada unidade experimental; biomassa seca da parte aérea aos 16, 25 e 46 DAS (cinco plantas); porcentagem de cobertura do solo pelos cultivares de soja aos 63 DAS, avaliada visualmente, atribuindo-se notas de zero (solo descoberto) até 100 (solo totalmente coberto); e rendimento de grãos, corrigindo-se a umidade para 13\%. Para determinação da biomassa seca da parte aérea, cinco plantas foram colhidas ao acaso por parcela, sendo posteriormente mantidas em estufa de circulação forçada de ar $\left(70 \pm 3{ }^{\circ} \mathrm{C}\right)$ por 72 horas. Após essa etapa, o material vegetal foi pesado em balança analítica.

Após a coleta e a tabulação dos dados, estes foram submetidos à análise de variância, sendo as médias dos parâmetros significativos comparadas pelo teste de Tukey a $5 \%$ de significância.

\section{RESULTADOS E DISCUSSÃO}

\section{Experimento 1 (cultivares de soja de ciclo precoce)}

Não foi observada interação entre os efeitos dos cultivares e dos manejos de plantas daninhas, em relação à altura das plantas de soja, em todas as épocas de avaliação.

Planta Daninha, Viçosa-MG, v. 23, n. 4, p. 575-581, 2005 
Detectou-se efeito significativo apenas para os cultivares. Aos 16 DAS, observou-se que os cultivares Monsoy 8001, Coodetec 204 e Emgopa 316 apresentaram altura de plantas superior à constatada nas plantas do cultivar Monsoy 6101 (Tabela 1). No entanto, aos 25 DAS, as plantas do cultivar Monsoy 6101 passaram a ter a maior altura, entre as demais avaliadas, apenas não diferindo do cultivar Emgopa 316, que apresentou aos 46 DAS maior altura de plantas, diferindo dos demais. Monsoy 8001 e Coodetec 204 apresentaram nessa última avaliação as plantas com menor porte. A altura de plantas é um componente importante na caracterização do potencial de competição da planta pela radiação solar. Shilling et al. (1995), avaliando o potencial competitivo de cinco cultivares de soja, verificaram que os que apresentaram maior altura foram menos prejudicados pela interferência de Senna obtusifolia.

Nas avaliações da biomassa seca da parte aérea realizadas aos 16 e 25 DAS (Tabela 2) não se constatou interação entre os cultivares e os manejos das plantas daninhas, diferindo da avaliação realizada aos 46 DAS, em que se constatou a interação desses fatores. Observase que as plantas do cultivar Monsoy 6101

Tabela 1 - Altura de plantas de quatro cultivares de soja de ciclo precoce. Rio Verde-GO, 2004

\begin{tabular}{|c|c|c|c|}
\hline $\begin{array}{l}\text { Cultivar de } \\
\text { soja }\end{array}$ & $\begin{array}{c}\text { Altura de plantas } \\
(\mathrm{cm}) \\
(16 \mathrm{DAS})\end{array}$ & $\begin{array}{c}\text { Altura de plantas } \\
(\mathrm{cm}) \\
(25 \mathrm{DAS})\end{array}$ & $\begin{array}{c}\text { Altura de plantas } \\
(\mathrm{cm}) \\
(46 \mathrm{DAS})\end{array}$ \\
\hline Monsoy 6101 & $15 \mathrm{~b}$ & $46 \mathrm{a}$ & $57 \mathrm{~b}$ \\
\hline Monsoy 8001 & $18 \mathrm{a}$ & $34 \mathrm{c}$ & $43 \mathrm{c}$ \\
\hline Coodetec 204 & $18 \mathrm{a}$ & $37 \mathrm{bc}$ & $48 \mathrm{c}$ \\
\hline Emgopa 316 & $18 \mathrm{a}$ & $42 a b$ & $73 \mathrm{a}$ \\
\hline
\end{tabular}

Médias seguidas de mesma letra não diferem entre si pelo teste de Tukey a 5\% de significância. DAS = dias após a semeadura. apresentaram maior biomassa seca da parte aérea aos 16 DAS, porém não diferindo do cultivar Emgopa 316. Nove dias após a primeira avaliação, para o cultivar Coodetec 204, que havia apresentado a menor biomassa seca de parte aérea, verificou-se amplo acúmulo de biomassa, sendo este agora o cultivar a apresentar o melhor desempenho nessa avaliação, não diferindo apenas do cultivar Monsoy 6101. $\mathrm{O}$ não-controle manual das plantas daninhas prejudicou o acúmulo da biomassa seca da parte aérea aos 46 DAS apenas das plantas provenientes do cultivar Coodetec 204 (Tabela 3), mostrando ser este o menos competitivo diante das plantas daninhas - para essa característica. Ainda aos 46 DAS, constata-se que nas parcelas mantidas livres da presença das plantas daninhas não houve diferença no acúmulo de biomassa seca da parte aérea entre todos os cultivares de ciclo precoce avaliados.

Na avaliação da porcentagem de cobertura do solo pelos cultivares de soja aos 63 DAS e do rendimento de grãos (Tabela 2), não se verificou interação entre os fatores cultivares

Tabela 3 - Biomassa seca da parte aérea de quatro cultivares de soja de ciclo precoce, em função de dois manejos de plantas daninhas, avaliada aos 46 dias após a semeadura. Rio Verde-GO, 2004

\begin{tabular}{|c|c|c|}
\hline \multirow{3}{*}{ Cultivar de soja } & \multicolumn{2}{|c|}{ Manejo das plantas daninhas } \\
\hline & Capinado & Não-capinado \\
\hline & \multicolumn{2}{|c|}{ Biomassa seca da parte aérea $(\mathrm{g})$} \\
\hline Monsoy 6101 & $37,25 \mathrm{aA}$ & $45,10 \mathrm{aA}$ \\
\hline Monsoy 8001 & $36,78 \mathrm{aA}$ & $35,25 \mathrm{aA}$ \\
\hline Coodetec 204 & $33,60 \mathrm{aA}$ & $21,00 \mathrm{bB}$ \\
\hline Emgopa 316 & $38,35 \mathrm{aA}$ & $35,75 \mathrm{aA}$ \\
\hline
\end{tabular}

Médias seguidas de mesma letra, minúscula na linha e maiúscula na coluna, não diferem pelo teste de Tukey a 5\% de significância.

Tabela 2 - Biomassa seca da parte aérea, porcentagem de cobertura do solo e rendimento de grãos de quatro cultivares de soja de ciclo precoce. Rio Verde-GO, 2004

\begin{tabular}{|c|c|c|c|c|}
\hline Cultivar de soja & $\begin{array}{l}\text { Biomassa seca da parte } \\
\text { aérea (g) (16 DAS) }\end{array}$ & $\begin{array}{c}\text { Biomassa seca da parte } \\
\text { aérea (g) (25 DAS) }\end{array}$ & $\begin{array}{c}\text { Cobertura do solo (\%) (63 } \\
\text { DAS) }\end{array}$ & $\begin{array}{c}\text { Rendimento de grãos } \\
\left(\mathrm{kg} \mathrm{ha}^{-1}\right)\end{array}$ \\
\hline Monsoy 6101 & $4,41 \mathrm{a}$ & $20,05 \mathrm{ab}$ & $80 \mathrm{~b}$ & $2.050 \mathrm{c}$ \\
\hline Monsoy 8001 & $3,40 \mathrm{bc}$ & $14,78 \mathrm{~b}$ & $88 \mathrm{a}$ & $2.111 \mathrm{bc}$ \\
\hline Coodetec 204 & $3,13 \mathrm{c}$ & $28,55 \mathrm{a}$ & $88 \mathrm{a}$ & $2.482 \mathrm{a}$ \\
\hline Emgopa 316 & $4,29 \mathrm{ab}$ & $15,74 \mathrm{~b}$ & $87 \mathrm{a}$ & $2.458 \mathrm{ab}$ \\
\hline
\end{tabular}

Médias seguidas de mesma letra não diferem entre si pelo teste de Tukey a 5\% de significância. DAS = dias após a semeadura. 
de soja e manejo das plantas daninhas, apenas havendo efeito significativo entre os fatores isoladamente. O cultivar Monsoy 6101 foi o que apresentou a pior porcentagem de cobertura do solo, sendo esta em torno de $8 \%$ a menos que a dos demais cultivares avaliados. A presença das plantas daninhas influenciou negativamente o fechamento do dossel, em todas os cultivares de soja (Tabela 4). A competição pelos recursos vitais água, luz e nutrientes, indisponibilizando estes para utilização pelas plantas de soja, acarretou diminuição na taxa de crescimento da cultura e, conseqüentemente, menor ocupação dos espaços. Voll et al. (2002) reportam que os cultivares de soja Embrapa-48 e Embrapa-62 comportaram-se de modo semelhante em relação às intensidades de competição de quatro espécies daninhas.

Na colheita do cultivar Coodetec 204 obteve-se o maior rendimento de grãos, apenas não diferindo do cultivar Emgopa 316 (Tabela 2), mostrando que mesmo sendo mais afetadas pela presença das plantas daninhas, quanto ao acúmulo de biomassa na parte aérea aos 16 DAS, as plantas do cultivar Coodetec 204 apresentam alto potencial produtivo. A presença das plantas daninhas durante o ciclo dos cultivares de soja reduziu em aproximadamente $250 \mathrm{~kg} \mathrm{ha}^{-1}$ a produção de grãos dos cultivares como um todo (Tabela 4).

\section{Experimento 2 (cultivares de soja de ciclo médio)}

Não foi verificada interação entre os efeitos dos cultivares e dos manejos de plantas daninhas em relação à altura das plantas de soja, em todas as épocas de avaliação (Tabela 5); apenas se detectou efeito significativo para os cultivares nas avaliações feitas aos 25 e 46 DAS. Esses resultados diferem dos relatados por Merotto Jr. et al. (2002), os quais observaram que a presença de plantas daninhas diminuiu a altura de plantas de soja. Na primeira avaliação da altura de plantas, realizada aos 16 DAS, constatou-se que as plantas de todos os cultivares de soja apresentaram altura média de $17 \mathrm{~cm}$. Na avaliação da altura de plantas aos 25 DAS, constatou-se que o cultivar Conquista apresentou plantas de maior altura, não diferindo, contudo, das plantas dos cultivares Emgopa 315 e Vencedora. Aos 46 DAS, a maior altura de plantas foi observada no cultivar Emgopa 315, sendo este superior a todos os demais cultivares.

Apenas se observou efeito significativo dos cultivares de soja sobre a biomassa seca da parte aérea das plantas na avaliação realizada aos 25 DAS (Tabela 6). Aos 16 DAS, as plantas de soja apresentaram valor médio de biomassa seca da parte aérea de 3,54 g, e aos 46 DAS de 32,95 g. O cultivar Emgopa 315 apresentou maior acúmulo de biomassa na parte aérea de suas plantas aos 25 DAS, porém não diferindo dos valores observados nos cultivares Vencedora e Coodetec 211 (Tabela 6). Merotto Jr. et al. (2002) constataram que a presença de plantas de Bidens subalternans provocou redução na biomassa de plantas de soja 16 dias após a emergência das plantas.

O cultivar que proporcionou o melhor sombreamento da área foi o Emgopa 315, o qual, aos 63 DAS, apresentava 93\% de cobertura do solo, porém não diferindo dos cultivares

Tabela 4 - Porcentagem média de cobertura do solo e rendimento médio de grãos de quatro cultivares de soja de ciclo precoce (Monsoy 6101, Monsoy 8001, Coodetec 204 e Emgopa 316), em função de dois manejos de plantas daninhas. Rio Verde-GO, 2004

\begin{tabular}{|l|c|c|}
\hline \multicolumn{1}{|c|}{ Manejo das plantas daninhas } & $\begin{array}{c}\text { Cobertura do } \\
\text { solo aos } \\
\text { 63 DAS }(\%)\end{array}$ & $\begin{array}{c}\text { Rendimento } \\
\text { de grãos } \\
\left(\mathrm{kg} \mathrm{ha}^{-1}\right)\end{array}$ \\
\hline Capinado durante todo o ciclo & $88 \mathrm{a}$ & $2.401 \mathrm{a}$ \\
\hline Não capinado durante todo o ciclo & $83 \mathrm{~b}$ & $2.150 \mathrm{~b}$ \\
\hline
\end{tabular}

Médias seguidas de mesma letra não diferem entre si pelo teste de Tukey a 5\% de significância. DAS = dias após a semeadura.

Tabela 5 - Altura de plantas de quatro cultivares de soja de ciclo médio. Rio Verde-GO, 2004

\begin{tabular}{|c|c|c|c|}
\hline Cultivar de soja & $\begin{array}{c}\text { Altura de } \\
\text { plantas (cm) } \\
(16 \text { DAS })\end{array}$ & $\begin{array}{c}\text { Altura de } \\
\text { plantas (cm) } \\
(25 \text { DAS })\end{array}$ & $\begin{array}{c}\text { Altura de } \\
\text { plantas (cm) } \\
\text { (46 DAS) }\end{array}$ \\
\hline Emgopa 315 & 18 & $39 \mathrm{ab}$ & $65 \mathrm{a}$ \\
\hline Conquista & 17 & $40 \mathrm{a}$ & $54 \mathrm{~b}$ \\
\hline Coodetec 211 & 16 & $34 \mathrm{~b}$ & $52 \mathrm{~b}$ \\
\hline Vencedora & 17 & $36 \mathrm{ab}$ & $46 \mathrm{~b}$ \\
\hline
\end{tabular}

Médias seguidas de mesma letra não diferem entre si pelo teste de Tukey a 5\% de significância. As médias não seguidas por letras indicam teste $\mathrm{F}$ não-significativo. $\mathrm{DAS}=$ dias após a semeadura.

Planta Daninha, Viçosa-MG, v. 23, n. 4, p. 575-581, 2005 
Tabela 6 - Biomassa seca da parte aérea, porcentagem de cobertura do solo e rendimento de grãos de quatro cultivares de soja de ciclo médio. Rio Verde-GO, 2004

\begin{tabular}{|c|c|c|c|c|c|}
\hline Cultivar de soja & $\begin{array}{c}\text { Biomassa seca da } \\
\text { parte aérea } \\
(16 \text { DAS })\end{array}$ & $\begin{array}{c}\text { Biomassa seca da } \\
\text { parte aérea } \\
(25 \text { DAS })\end{array}$ & $\begin{array}{c}\text { Biomassa seca da } \\
\text { parte aérea } \\
(46 \text { DAS })\end{array}$ & $\begin{array}{c}\text { Cobertura do solo } \\
(\%) \\
(63 \text { DAS })\end{array}$ & $\begin{array}{c}\text { Rendimento de grãos } \\
\left(\mathrm{kg} \mathrm{ha}^{-1}\right)\end{array}$ \\
\hline Emgopa 315 & 3,45 & $23,16 \mathrm{a}$ & 33,39 & $33 \mathrm{a}$ & 2.889 \\
\hline Conquista & 3,76 & $13,18 \mathrm{~b}$ & 37,10 & $88 \mathrm{ab}$ & 2.278 \\
\hline Coodetec 211 & 3,25 & $14,01 \mathrm{ab}$ & 26,98 & $85 \mathrm{~b}$ & 2.542 \\
\hline Vencedora & 3,69 & $17,06 \mathrm{ab}$ & 34,33 & $89 \mathrm{ab}$ & 2.570 \\
\hline
\end{tabular}

Médias seguidas de mesma letra não diferem entre si pelo teste de Tukey a 5\% de significância. As médias não seguidas por letras indicam teste $\mathrm{F}$ não-significativo. DAS = dias após a semeadura.

Vencedora e Conquista (Tabela 6). A presença das plantas daninhas prejudicou significativamente o fechamento do dossel (Tabela 7). As parcelas mantidas livres da infestação das plantas daninhas apresentavam em média 90\% de cobertura do solo, contra $87 \%$ quando não se realizaram as capinas manuais.

Os resultados do rendimento de grãos por cultivar estão apresentados na Tabela 6. O rendimento médio observado entre os cultivares foi de $2.570 \mathrm{~kg} \mathrm{ha}^{-1}$. As plantas daninhas ocasionaram perda média no rendimento de grãos de soja de aproximadamente $480 \mathrm{~kg} \mathrm{ha}^{-1}$, independentemente do cultivar avaliado (Tabela 7). Voll et al. (2002) constataram reduções crescentes no rendimento de grãos da cultura da soja quando em competição com densidades progressivas das plantas daninhas Euphorbia heterophylla, Brachiaria plantaginea, Ipomoea grandifolia e Senna obtusifolia.

Constatou-se que todos os cultivares de soja, seja de ciclo precoce ou médio, apresentaram quedas no rendimento de grãos com o não-controle das plantas daninhas.

Tabela 7 - Porcentagem média de cobertura do solo e rendimento médio de grãos de quatro cultivares de soja de ciclo médio (Emgopa 315, Conquista, Coodetec 211 e Vencedora), em função de dois manejos de plantas daninhas. Rio Verde-GO, 2004

\begin{tabular}{|l|c|c|}
\hline \multicolumn{1}{|c|}{ Manejo das plantas daninhas } & $\begin{array}{c}\text { Cobertura do } \\
\text { solo aos } \\
\text { 63 DAS }(\%)\end{array}$ & $\begin{array}{c}\text { Rendimento } \\
\text { de grãos } \\
\left(\mathrm{kg} \mathrm{ha}^{-1}\right)\end{array}$ \\
\hline Capinado durante todo o ciclo & $90 \mathrm{a}$ & $2.809 \mathrm{a}$ \\
\hline Não capinado durante todo o ciclo & $87 \mathrm{~b}$ & $2.330 \mathrm{~b}$ \\
\hline
\end{tabular}

Médias seguidas de mesma letra não diferem entre si pelo teste de Tukey a 5\% de significância. DAS = dias após a semeadura.
Pela análise conjunta de todas as características avaliadas, constata-se que, entre os cultivares de ciclo precoce, Emgopa 316 e Coodetec 204 mostraram ser os mais competitivos com as plantas daninhas. Da mesma forma, para os cultivares de ciclo médio, verifica-se que Emgopa 315 destaca-se quanto ao seu potencial de competição com as espécies invasoras. Pode-se concluir que os cultivares de soja Emgopa 316 e Coodetec 204 (ciclo precoce) e Emgopa 315 (ciclo médio) são os mais indicados para serem cultivados em áreas com maior incidência de plantas daninhas.

\section{LITERATURA CITADA}

ALMEIDA, M. L.; MUNDSTOCK, C. M.; SANGOI, L. Conceito de ideotipo e seu uso no aumento do rendimento potencial dos cereais. Ci. Rural, v. 28, p. 325-332, 1998.

BLACKSHAW, R. E. et al. Integration of cropping practices and herbicides improves weed management in dry bean (Phaseolus vulgaris). Weed Technol., v. 14, p. 327-336, 2000.

COX, W. J. et al. Agronomics and economics of different weed management systems in corn and soybean. Agron. J., v. 91, p. 585-591, 1999.

JOHNSON, M. D.; WYSE, D. L.; LUESCHEN, W. E. The influence of herbicide formulation on weed control in four tillage systems. Weed Sci., v. 37, p. 239-249, 1989.

JOHNSON, G. A.; HOVERSTAD, T. H.; GREENWALD, R. E. Integrated weed management using narrow row crop spacing, herbicides and cultivation. Agron. J., v. 90, p. 40-46, 1997.

LINDQUIST, J. L.; MORTENSEN, D. A.; JOHNSON, B. E. Mechanisms of corn tolerance and velvetleaf suppressive ability. Agron. J., v. 90, p. 787-792, 1998. 
MEROTTO JR., A.; VIDAL, R. A.; FLECK, N. G. Variação da competição interespecífica em milho em função do controle de plantas daninhas em faixas. Planta Daninha, v. 19, p. 287-294, 2001.

MEROTTO JR., A. et al. Interferência das plantas daninhas sobre o desenvolvimento inicial de plantas de soja e arroz através da qualidade da luz. Planta Daninha, v. 20, p. 9-16, 2002.

PURICELLI, E. C. et al. Spurred Anoda (Anoda cristata) competition in narrow and wide-row soybean (Glicine max). Weed Technol., v. 17, p. 446-451, 2003.

SEIBERT, A. C.; PEARCE, R .B. Growth analysis of weed and crop species with reference to seed weight. Weed Sci., v. 41 , p. 52-56, 1993.
SHAW, D. R.; RANKINS Jr., A.; RUSCOE, J. T. Sicklepod (Senna obtusifolia) interference with soybean (Glycine max) cultivars following herbicide treatments. Weed Technol., v. 11, p. 510-514, 1997.

SHILLING, D. G. et al. Effect of soybean (Glycine max) cultivar, tillage, and rye (Secale cereale) mulch on sicklepod (Senna obtusifolia). Weed Technol., v. 9, p. 339-342, 1995.

SILVA, A. A. et al. Controle de plantas daninhas. Brasília, DF: ABEAS, 2000. 260 p.

TOLLENAAR, M. et al. Effect of crop density on weed interference in maize. Agron. J., v. 86, p. 591-595, 1994.

VOLL, E. et al. Competição relativa de espécies de plantas daninhas com dois cultivares de soja. Planta Daninha, v. 20, p. 17-24, 2002. 